Paul Flechsig's System of Myelogenetic Cortical Localization in the Light of Recent Research in Neuroanatomy and Neurophysiology - Part I - Alfred Meyer.

The Computerized Tomographic Appearance of Angiographically Occult Arterlovenous Malformations of the Brain - Richard Leblanc and Romeo Ethier

A Comparison of Visual, Brainstem Auditory, and Somatosensory Evoked

Potentials in Multiple Sclerosis - S.J. Purves, M.D. Low, J. Galloway and B. Reeves

Task Dependent Variations of Ocular Lateropulsion in Wallenberg's Syndrome - T.H. Kirkham, D. Guitton and M. Gans

Effect of Therapy on Cerebral Blood Flow Following Aneurysm Surgery Bryce Weir, Roberto DeLeo and Devidas Menon

Method of Addition of Bromocriptine to the Drug Regime of Patients with Advanced Parkinson's Disease - J. David Grimes and Mohamed N. Hassan

Multiple Sclerosis and Associated Diseases: A Relationship to Diabetes Mellitus Sharon Warren and K.G. Warren

University of Toronto Neurosurgical Rounds No. 4

Global Arteriovenous Malformation of the Cervical Region - R.C. Holgate and W.M. Lougheed ......

Treatment of Fisher's Variant of Guillain-Barre Syndrome by Exchange Transfusion Allan T. Irvine and John Tibbles

Myoclionies du voile associées à une diminution de l'acide 5-hydroxy-indole-acétlque céphalorachidien et répondant au clonazepam - S. Gauthier, S.N. Young and D.W. Baxter

Friedreich's Ataxia with Nephrotic Snydrome and Convulsive Disorder: Clinical and Neurophysiological Studies with Renal and Nerve Blopsies and an Autopsy G.V. Watters, S.H. Zlotkin, B.S. Kaplan, P. Humphreys and K.N. Drummond

The Effect of Several Intertrial Intervals on the $1 \mathrm{~Hz}$ Interference Effect John Gaito and Stephen T. Gaito

Multiple Regression Analysis of Diagnostic Predictors in Optic Nerve Disease T.H. Kirkham and S.G. Coupland

Structural Lesions of the Brain in Young Schizophrenics - P. Averback

Delayed Encephalopathy Following Carbon Monoxide Intoxication G.M. Sawa, C.P.N. Watson, K. Terbrugge and M. Chiu

The Crossed Adductor Reflex In Humans: An EMG Study - Robert D. Teasdall and H. van den Ende ...

John William Magladery - Robert D. Teasdall

Spinal Subdural Hematoma in Association with Anticoagulant Therapy

Neville Russell, F.B. Maroun, J.C. Jacob

Valproic Acid and Plasma Levels of Primidone and Derived Phenobarbital - J. Bruni 
Paul Flechsig's System of Myelogenetic Cortical Localization in the Light of Recent Research in Neuroanatomy and Neurophysiology: Part II - Alfred Meyer

Experimental Porphyric Neuropathy: A Preliminary Report - Anders A.F. Sima, James C. Kennedy,

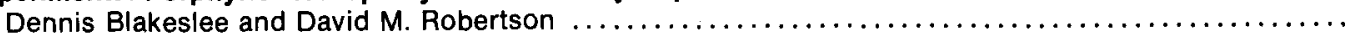

University of Toronto Neurosurgical Rounds No. 5 - Extraneural Metastases of a Cerebral Astrocytoma - Harold J. Hoffman, Larry E. Becker, Derek Jenkin, Sylvester H. Chuang and lan R. Munro

The Computed Tomographic Assessment of Brain Infarcts - D.E. Tubman, R. Ethier, D. Melancon, G. Belanger, and S. Taylor...

Neuropsychological Changes Following Carotid Endarterectomy - Robert A. Bornstein, Brien G. Benoit, Ronald L. Trites.

Positional Vertigo and Nystagmus of Central Origin - R. Watson, H.O. Barber, J. Deck and K. Terbrugge 133

Chronic Levodopa and Renal Function - Margaret M. Hoehn

Immunofluorescent Staining of Rat Brain Glial Cells with Multiple

Sclerosis Serum - Vijendra K. Singh and Robert D. Mashal

Polymyositis Presenting with Distal and Asymmetrical Weakness

- Mecheri B. Sundaram and Edward M. Ashenhurst

Spinal Cord Swelling in Multiple Sclerosis - Thomas E. Feasby, Donald W. Paty, George C. Ebers and Allan J. Fox

Pitfalls in Posterior Fossa CT Scanning: An Illustrative Case Report - Fraser W. Saunders and Bruce I. Tranmer

Neurenteric Cysis of the Spinal Cord Mimicking Multiple Sclerosis - H.V. Vinters and J.J. Gilbert

Pasteurella Multocida Subdural Empyema: A Case Report

- Mohamed Ibrahim Khan and Richard Chan

Dopamine Uptake Capacity of Platelets From People at Risk for

Huntington's Chorea - Donald R. McLean and Taichi Nihei

The Effect of Plasmapheresis on Post-Thymectomy Ocular Dysfunction

- C.W. Olanow, A.D. Roses, and J.W. Fay

Abnormal Proximal Axons of Clarke's Neurons in Sporadic Motor Neuron Disease

- P. Averback and P. Crocker

Anoxic Tonic Seizures Due to Asthma: A Serious Complication in Adults

- Daniel L. Keene, Calvin A. Melmed, Frederick Andermann, and Donald W. Baxter

A Case of Huntington's Chorea with Unilateral Ectopic Gray Matter

- Haring J. W. Nauta and M.E. Platts

Program Abstracts of the XVI Canadian Congress of Neurological Sciences 
Message from the Editor

Trigeminal Neuralgia: A Comparison of the Results of Percutaneous Rhizotomy and Microvascular Decompression - G.G. Ferguson, D.C. Brett, S.J. Peerless, H.W.K. Barr, J.P. Girvin .. 207

Cerebrovascular Permeability in Mechanically Induced Hypertension - Sukriti Nag, David M. Robertson, Henry B. Dinsdale

Occult Fifth Nerve Dysfunction in

Multiple Sclerosis - Andrew Eisen, Donald Paty, Sherrill Purves, and Maureen Hoirch

Abnormal Adaptation of Visual Contrast Sensitivity

in Multiple Sclerosis Patients - J. Raymond, Regan, and T.J. Murray

Intraoperative Regional Cerebral Blood Flow During

Carotid Endarterectomy - David M. Rowed and Mikios I. Vilaghy ....................... 235

Abnormal Electroretinograms and Visual Evoked Potentials in Chronic Papilledema

using Time-Difference Analysis - T H Kirkham and S. G. Coupland

The Effect of Low Frequency and Direct Current Stimulation on the

Kindling Phenomenon in Rats - John Gaito

Conference Report - The Torsion Dystonias:

A Summary of the Third Dystonia Workshop - Edward G. Harris $\ldots \ldots \ldots \ldots \ldots \ldots \ldots \ldots \ldots \ldots .255$

Effects of Ethyl Ester Derivatives of Valproic Acid Metabolites

on Pentylenetetrazol Seizures in Mice - J. Bruni, E.J. Hammond, and B.J. Wilder .

Brain Stem Glioma in Childhood: Acute Hemiplegic Onset - S.J. Rothman and C.W. Olanow

Book Reviews

Notes and Announcements

\section{THE CANADIAN JOURNAL OF NEUROLOGICAL SCIENCES}

VOL. 8 NO. 4 NOVEMBER 1981

Dr. Derek Denny-Brown: An Appreciation - R.W. Gilliat

Viewpoint: What the marine mollusc Aplysia can tell the neurologist about behavioral neurophysiology, - P. Ruben, J. Goldberg, J. Edstrom,

K. Voshant and K. Lukowiak

Porphyric Neuropathy: An Ultrastructural and Quantitative Case Study

- P.S. Thorner, J.M. Bilbao, A.A.F. Sima and S. Briggs

An Electroretinal and Visual Evoked Potential Study in Friedreich's Ataxia

- T.H. Kirkham and S.G. Coupland

Lumbar Stenosis: Analysis of Factors Affecting Outcome in 81 Surgical

Cases - B. Weir and R. de Leo

Life Effects of Narcolepsy in 180 Patients from North America, Asia and

Europe Compared to Matched Controls - R. Broughton, Q. Ghanem, Y. Hishikawa

Y. Sugita, S. Nevsimalova and B. Roth

Effect of L-Tryptophan on Spasmodic Torticollis - S. Lal, S.N. Young,

M.E. Kiely, K. Hoyte, D.W. Baxter and T.L. Sourkes 
Meningitis and Brain Abscess Due to Clostridium Perfringens and Clostridium Paraputrificum Following Orbital Trauma - Y. Girouard, G. Delage,

Neonatal Myotubular Myopathy: Neuropathy and Failure of Postnatal Maturation

of Fetal Muscle - H.B. Sarnat, S.I. Roth and J.F. Jiminez

Clinical Progression of Giant-Axonal Neuropathy over a Twelve Year Period

- J. M. Dooley, Y. Oshima, L.E. Becker and E.G. Murphy

A Simple and Reproducible Experimental in Vivo Glioma Model - R.N. Auer,

R.F. Del Maestro and R. Anderson

Conference Report: International Symposium on Multiple Sclerosis - S. Dales,

G. Ebers, T. Feasby and D. Paty

Notes and Announcements 


\section{THE ROYAL COLLEGE OF PHYSICIANS AND SURGEONS OF CANADA \\ with the co-operation of the Canadian Neurosurgical Society announces}

\section{THE K.G. McKENZIE MEMORIAL AWARDS \\ to honour the memory of \\ Canada's pioneer neurosurgeon}

AWARD 1.A citation and prize of $\$ 100.00$ will be awarded for the best paper presented to the annual meeting of the Canadian Neurosurgical Society by a neurosurgical resident in which he is the principal author. The recipient, as well, will have his expenses, including Air Fare, Hotel Accommodation and Registration Fees, paid for as part of the Award.

AWARD 2. A grant-in-aid will be awarded to support a specific educational project which may include travel. (However, travel to regularly scheduled neurosurgical meetings is excluded.) The applicant must be a resident in training in a Canadian Neurosurgical Training Program, or if formal training is completed, within two years of having received certification in neurosurgery.

APPLICATIONS FOR AWARD 1. Papers should be received by the chairman of the Awards Committee not later than January 15. All papers received will be automatically fowarded to the program chairman for the annual meeting of the Canadian Congress of Neurological Sciences for further consideration. The successful candidate will be notified by April 1, and the awards will be presented at the annual meeting in June.

APPLICATIONS FOR AWARD 2. Applicants should foward a comprehensive letter to the chairman of the Awards Committee by January 15. The application should contain relevant personal information, a clear description of the educational project which is contemplated, and its purpose, and any supporting letters the applicant may wish to submit. The successful applicant will be notified by April 1.

\section{APPLICATIONS SHOULD BE SENT TO:}

Chairman

K.G. McKenzie Memorial Awards Committee

Room 2-113 Centennial Wing, Victoria General Hospital

HALIFAX, Nova Scotia

\section{FELLOWSHIP IN NEUROSCIENCE One Year Appointment}

Full time position available in the Department of Neuroscience of a large Medical Center affiliated with Northwestern University Medical School. Responsibilities include: Evoked Potentials, Electric Encephalography and 24hour Holter E.E.G.'s.

Three years of experience in neuroscience with emphasis on neurology and in-patient and out-patient procedures preferred. The selected appointee will be working with other professionals associated with Loyola University Stritch School of Medicine and the University of Illinois Medical Center.

Cover letter and curriculum vitae of interested candidates should be sent to:

D. M. VUCKOVICH M.D.

Vice President, Neuroscience

Columbus-Cuneo-Cabrini Medical Center

2520 North Lakeview Avenue

Chicago, Illinois 60614

Equal Opportunity Employer M/F

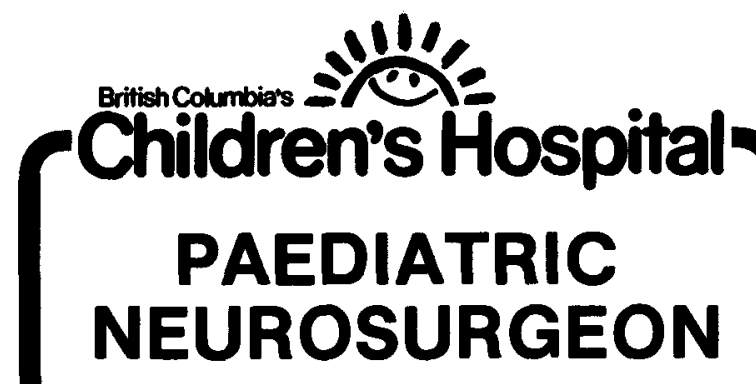

Academic Paediatric Neurosurgeon sought for the B.C. Children's Hospital which will be opening in late 1981. Paediatric Neurosurgery in Vancouver will be concentrated in this hospital which will start as a Tertiary Care Facility for a population of $2-1 / 2$ million.

Please address responses to:

D.F. Hardwick, M.D.

Chairman, Search Committee

CHILDREN'S HOSPITAL

250 West 59th Avenue

Vancouver, B.C.

V5X 1X2 


\section{The HADASSAH MEDICAL ORGANIZATION invites applications for the post of HEAD OF THE DEPARTMENT OF NEUROSURGERY}

at the Hadassah University Hospital, Kiryat Hadassah, Jerusalem.

Candidates should have a rich experience in all aspects of neurosurgery, and also extensive teaching and research accomplishments.

The post is linked with high academic status in the Hebrew University-Hadassah Medical School.

Applications and enquiries, accompanied by cirriculum vitae and list of publications, may be addressed to the Director General, Hadassah Medical Organization, Kiryat Hadassah, Jerusalem, Israel until December 31, 1981.

Cerebro-vascular Research Fellow. Full-time position available for one year starting July 1982 for clinical investigation of acute stroke. Research activities located in the non-invasive cerebrovascular laboratory (cerebral blood flow and Doppler ultrasound) attached to the MacLachlan Stroke Unit. Reply to: Dr. J.W. Norris, Dept. of Neurosciences, Sunnybrook Medical Centre, 2075 Bayview Avenue, Toronto, Ontario, Canada.

\section{ERRATUM}

In the article entitled "The Computerized Tomographic Appearance of Angiographically Occult Arteriovenous Malformations of the Brain" by Richard Leblanc and Romeo Ethier which appeared in Volume 8, Number 1 (Feb), page 7 , there was an omission in the Discussion section. The sentence on page 10 , line 23 should read "Contrary to the angiographic appearance, the vascular nature of the lesions was suggested by the CT finding of vascular enhancement in $62 \%$ of the cases".

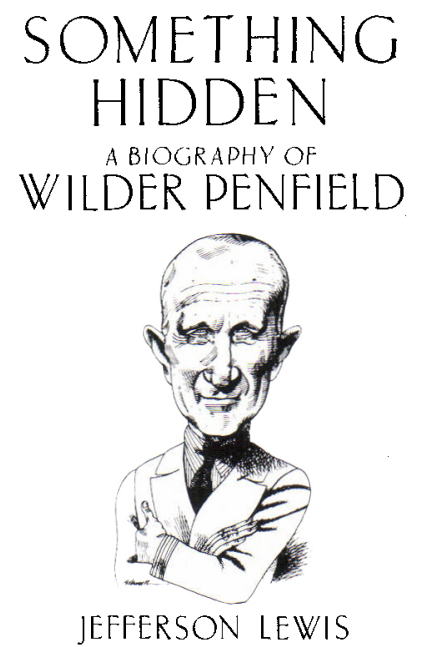

SOMETHING HIDDEN: A Biography of Wilder Penfield by lefferson Lewis. "Brain surgery is a terrible profession," wrote Wilder Penfield in New York in 1921. "If I did not feel it will become different in my life time, I should hate it." SOMETHING HIDDEN is the first biography of a remarkable medical pioneer and the most famous brain surgeon of his generation. Wilder Penfield founded the Montreal Neurological Institute and revolutionized the treatment of disorders of the brain. A compelling and controversial figure in Canada's medical history. $\$ 19.95 ; 56$ black and white photographs.

\section{Medical History from Doubleday}

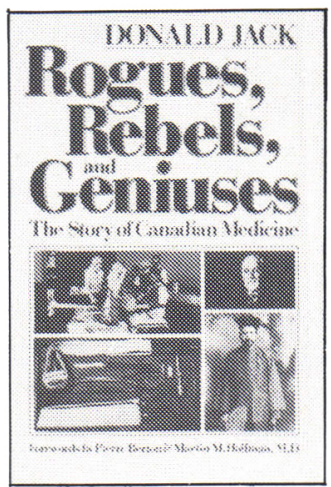

ROGUES, REBELS, AND GENIUSES: The Story of Canadian Medicine by Donald lack. Forewords by Pierre Berton and Dr. Martin Hoffman.

A dramatic, informative, and absorbing story of more than 400 years of medicine in Canada, including such famous names as Grenfell, Osler, Bethune, Penfield and Banting.

$\$ 24.95 ; 69$ black and white photographs. 


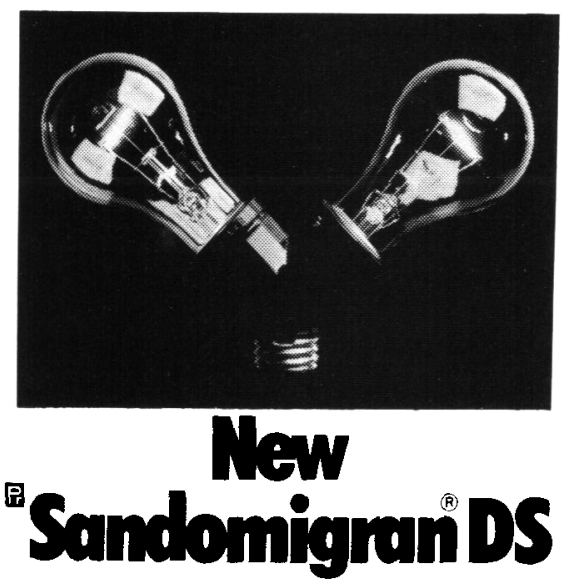

Specific, Double Strength headache prophylaxis.

PRESCRIBING INFORMATION

SANDOMIGRAN (pizotyline)

SANDOMIGRAN D.S.

Dosage - The average mantenance dosage is $05 \mathrm{mg}$ ti d A

progressive dosage is recommended unti ithe fitth day of theropy

The dosage range is 1 to $6 \mathrm{mg}$ per do

Since vascular headache is a paroxysmal but basically chronic disorder, treatment must exteıd over an adequate period of time in order to obta in moximal benefit While some patients have

esponded rather quickly, most investigotors ogree that a four-week mian period shrould be insituled to determine the true efficacy of pizonine in specific coses. The periodic nalure or the disorder will have to be considered in delermining when and for how ong therapy change in headache potren som change in headache pattern affer several months of thercpy. con coninumg leatmen. The dosage should be reduced grodually turing the lost two we

Composition - Each ivory. sugar-coated tablet contans $0.5 \mathrm{mg}$ of pizotyline as the hydrogen malate Each single scored white tobte contains $1 \mathrm{mg}$ of pizotyline as the hydrogen malat

Contraindications - Anticholinergic agents including pizotyline are contraind icoted in potients toking monoomine oxidose inhibitors and in patients with pyloroduodenal obstruction and stenosing pyloric ulcer Pizotyline is a'so contrandicated for patients who have a known sensitivity to the drug. Until further studies are completed the drug is not recommended for children under the age of welve Warnings and precoutions - Since drowsiness may occur with pizotyline sensitive pottents should be coutioned agoinst activities requiring ropid and precise response ( 1 e driving an outomobile or operat tn dongerous machinery) until the r response to the drug has oper those of other drugs affecting the cental nervous system patients should be coutioned agains d dinking olcoholic beveroges or taking hyprotics sedotives psychotherapeutic ogents or other drugs with CNS depressont effects during pizotyline theropy. Administer pizotyline with caution to patients with narrow angle glaucoma or with urinary retention (e g. prostatic hypertrophy)

Since it is desirable to keep drug administration to a minimum duririg pregrioncy, pizonyline should be given only when the benetils derived from treatment exceed the possibie risks to mother and fetus Some pattents developed tolerance to pizotyline with prolonged use of the drug An increase in dosage may overcome this tolerance After prolonged use, hepatotoxic effects might occur and patients should be advised to report for adequate laboratory evaluation Patients with diobetes cardiovoscul or diseose and known or suspected imparred renal or hepalic function should be given pizotyline with coution and appropricte loboratory lests should be

done at regular intervols
Lens opocities occurred in two cases bur did not appear to be drug-related. However. if is recommended that any impoirment in vision be reported to the attending physician for further investigation Side effects - Increcsed appetite, weight gain, and drowsiness are the most freauent side effects An appropriate diet should be

recommended by the physician for potients benefiting from the drug but gaining excessive weight. A gradual increose in the dosage of pizotyline is recommended to minimize or reduce the incidence of drowsiness. The following adverse effects hove been observed less frequently in relation to the oforementioned reoctions: foligue.

nausea dizziness, headoche. confusion, edemo, hypo'ension. depression, weokness, epigastic distress dry mouth, nervousness. impotence and muscle pain

Supply - $05 \mathrm{mg}$ tablets in bottles of 100 and $500.1 \mathrm{mg}$ scored table's in bottles of 100

Complete prescribing information avoilable on request

PAAB
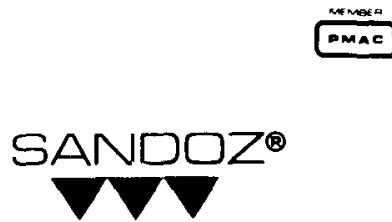

Sandoz (Canada) Limited, Dorval, Quebec

\section{Prolopa Roche}

Rx Summary

Indlcatlons

Treatment of Parkinson's syndrome with the exception of drug-induced parkinsonism.

Contraindlcations

Known hypersensitivity to levodopa and/or benserazide. in patients in whom sympathomimetic amines are contraindicated; in conjunction with monoamine oxidase inhibitors or within two weeks of their withdrawal. Clinica or laboratory evidence of uncompensated cardiovascular, endocrine, renal, hepatic, hematologic or pulmonary disease; narrow-angle glaucoma (may be used in wideangle glaucoma provided intraocular pressure remains under control). History of melanoma or suspicious undiagnosed skin lesions.

\section{Warnings}

Discontinue levodopa therapy at least 12 hours before initiating 'Prolopa' therapy. Increase dosage of

'Prolopa' 100-25 gradually to avoid inducing CNS side effects (abnormal movements). Observe patients for signs of depression with suicidal tendencies or other serious behavioural changes. Caution in patients with history of psychotic disorders or those receiving reserpine, phenothiazines or tricyclic antidepressants.

Administer with care to patients with history of myocardial infarction or who have atrial, nodal or ventricula arrhythmias.

Safety in patients under 18 years has not been established. In women who are or may become pregnant benefits should be weighed against possible hazards to mother and fetus. Should not be given to nursing mothers.

\section{Precaution:}

Caution in patients with history of convulsive disorders Upper gastrointestinal hemorrhage possible in patients with history of peptic ulcer.

Normal activity should be resumed gradually to avoid risk of injury

Administer with caution to patients on antihypertensive medication; discontinue 12 hours before anesthesia. Monitor intraocular pressure in patients with chronic wide-angle glaucoma.

\section{Adverse reactions}

Most common are abnormal involuntary movements, usually dose dependent, and may disappear or become tolerable after dosage reduction.

Most serious after prolonged therapy are periodic oscit lations in performance (end of dose akinesia, on-off phenomenon and akinesia paradoxica).

Nausea, vomiting, arrythmias and orthostatic hypotension occur less frequently than with levodopa alone. Psychiatric disturbances, including mild elation, depression, anxiety, agitation, aggression, hallucinations and delusions have been encountered.

Consult monograph for complete list of reported adverse effects.

Dosage

Recommended initial dose is one capsule 'Prolopa' 100-25 once or twice daily, increased carefully by one capsule every third or fourth day until an optimum therapeutic effect is obtained without dyskinesias. At upper limits of dosage increments should be made slowly at 2 to 4 -week intervals.

Optimal dosage for most patients is 4 to 8 capsules of Optimal dosage for most patients is 4 to 8 capsules of Prolopa' $100-25$ daily ( $400-800 \mathrm{mg}$ levodopa) divided 6 capsules 'Prolopa' $100-25$ ( $600 \mathrm{mg}$ levodopa) per day. 6 capsules 'Prolopa' $100-25$ (600 mg levodopa) per day. 'Prolopa' 200-50 capsules are intended only for maintenance therapy once the optimal dosage has been deter-
mined using 'Prolopa' 100-25 capsules. No patients should receive more than 5 to 6 capsules 'Prolopa' 200-50 daily ( 1000 to $1200 \mathrm{mg}$ levodopa) during the first year of treatment.

For patients previously treated with levodopa discontinue for 12 hours and initiate with 'Prolopa' 100-25 to provide approximately $15 \%$ of previous levodopa dosage. The

initial daily dose, however, should not exceed 6 capsules

'Prolopa' 100-25 divided into 4 to 6 doses.

Supply

Blue flesh-coloured capsules imprinted ROCHE C and PROLOPA 100-25 (black ink) alternating between body and cap each containing $100 \mathrm{mg}$ levodopa and $25 \mathrm{mg}$ benserazide.

Blue, caramel-coloured capsules imprinted ROCHE $C$ and PROLOPA 200-50 (black ink) alternating between body and cap, each containing $200 \mathrm{mg}$ levodopa and $50 \mathrm{mg}$

benserazide.

Bottles of 100

Product monograph available on request.

(1) Reg.Trade Mark

'Prolopa' is listed in provinclal formularies.

ROCHE Hoffmann-La Roche Limited Vaudreuil, Québec J7V 6B3 this publication is available in microform

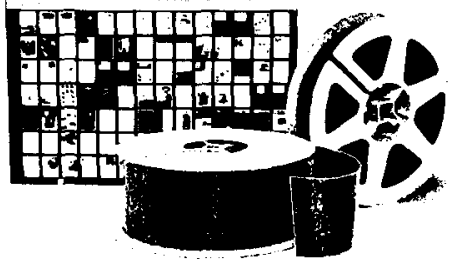

Please send me additional information. University Microfilms International 300 North Zeeb Road 18 Bedford Row Dept. P.R

Ann Arbor, MI 48106

Dept.P.R.

U.S.A.

London, WC1R 4EJ

England

Name

Institution

Street

City

State Zip

How doyou spell truth in advertising?

\section{PAAB \\ C CPP}

This logo appearing on pharmaceutical advertisements in proiensanal journals moans that the advertisements hav meceutcal Advertising Advisory Board/Consell Consultath de Publicite Pharmaceutique.

This unique tor ing is the first of ha kind in North America. The Board of Directors is composed of individuals representing the following organizallons: Aasociellon des labricants du

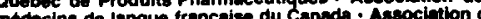
modical india . Conedlen Advertising Advisory Band. cersecit Clon - Cenedian Pharmaceutical Association - Consumers' Aesociation of Cansda.

Ascociation of Can

The Health Protection Branch of Heatth and Welfare Cened

The program ensures the accuracy of phermaceutical advertiaing to the health professions, so that $1 \mathrm{may}$ 


\section{INDEX TO ADVERTISEMENTS}

Beckman EEG - (xii)

Frosst, Entrophen - (x) and (xi)

Geigy, Tegretol - outside back cover and Lioresal - (viii)

Grass Instruments, Polysomnographic Recording (xx)

Heerbrugg Microscopes - (xiii)

Hoffman-LaRoche, Rivotril (ii), (xix) and (xxi) Prolopa (xxii) and (xvii)

Parke Davis, Dilantin, Zarontin - (i) and (xviii)

Sandoz Pharmaceuticals, Fiorinal - (vii) and (xviii) New Sandomigran DS - (iii) and (xvii)

Unimed Canada, Serc - inside front cover
(ASA U.S.P. $330 \mathrm{mg}$ (C) Sandoptal (B) (butalbital) $50 \mathrm{mg}$, caffeine U.S.P. $40 \mathrm{mg}$.)

Contraindlcations

Porphyria, hypersensitivity to any of the components.

\section{Precautions}

Due to the presence of butalbital Fiorinal may be habit-forming. Excessive or prolonged use should be avoided.

Activities requiring mental alertness should not be undertaken until the patient's response and sensitivity to the medication have been established.

Fiorinal should be used with caution in the presence of peptic ulcer.

During pregnancy and lactation, Fiorinal should be taken only upon medical advice.

Adverse reactions

Drowsiness, dizziness, nausea, constipation and skin rash may occur in rare instances.

Dosage

Adults, 2 tablets or capsules at once, followed if necessary, by 1 tablet or capsule every 3 to 4 hours, or as directed by the physician. Maximum daily dose: 6 tablets or capsules.

Children, 1 to 3 tablets or capsules a day, according to age.

Supply

Capsules or Tablets, bottles of 100 and 500

1. Federal Register, Vol. 42, No. 220:

59115. Tuesday, November 15, 1977.

Complete prescribing information available on request.

Sandoz (Canada) Limited

P.O. Box 385, Dorval, Quebec H9R 4P5

\section{BRIEF PRESCRIBING INFORMATION}

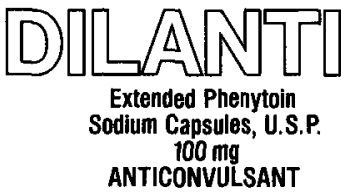

\section{INDICATIONS}

Dilantin is indicated for the control of generalized tonic-clonic (grand mal) seizures and complex partial (psychomotor) seizures.

\section{CONTRAINDICATIONS}

Dilantin is contraindicated in those patients with a history of hypersensitivity to hydantoin products.

\section{WARNINGS}

Abrupt withdrawal of phenytoin in epileptic patients may precipitate status epilepticus. Phenytoin is not indicated in seizures due to hypoglycemia or other causes which may be immediately identified and corrected.

Phenytoin metabolism may be significantly altered by the concomitant use of other drugs such as:

A Barbiturates may enhance the rate of metabolism of phenytoin. This effect, however, is variable and umpredictable. It has been reported that in some patients the concomitant administration of carbamazepine resulted in an increased rate of phenytoin metabolism.

B Coumarin anticoagulants, disulfiram phenylbutazone, and sulfaphenazole may inhibit the metabolism of phenytoin, resulting in increased serum levels of the drug. This may lead to an increased incidence of nystagmus, ataxia, or other toxic signs. C Isoniazid inhibits the metabolism of phenytoin so that with combined therapy, patients who are slow acetylators may suffer from phenytoin intoxication.

D Tricyclic antidepressants in high doses may precipitate seizures, and the dosage of phenytoin may have to be adjusted accordingly.

Usage in Pregnancy: The effects of Dilantin in human pregnancy and nursing infants are unknown.

The prescribing physician will have to determine the risk/benefit in treating or counselling epileptic women of childbearing potential.

\section{PRECAUTIONS}

The liver is the chief site of biotransformation of phenytoin patients with impaired liver function may show early signs of toxicity. Elderly patients or those who are gravely ill may show early signs of toxicity.

A small percentage of individuals who have been treated with phenytoin have been shown to metabolize the drug slowly. Slow metabolism may be due to limited enzyme availability and lack of induction; it appears to be genetically determined.

Phenytoin has been associated with reversible lymph node hyperplasia. If lymph node enlargement occurs in patients on phenytoin, every effort should be made to substitute another anticonvulsant drug or drug combination.

Drugs that control generalized tonic-cionic (orand mal) seizures are not effective for absence (petit mal) seizures. Therefore, if both conditions are present, combined drug therapy is needed.

Hyperolycemia, resulting from the drug's in hibitory effect on insulin release has been reported. Phenytoin may also raise the blood sugar level in persons already suffering from hyperglycemia.

\section{ADVERSE REACTIONS}

Central Nervous System: The most common manifestations encountered with phenytoin therapy include nystagmus, ataxia, slurred speech, and mental confusion. Dizziness, insomnia, transient nervousness, motor twitchings, and headache have also been observed. These side effects may disappear with continuing therapy at a reduced dosage level.

Gastrointestinal System: Phenytoin may cause nausea, vomiting, and constipation. Administration of the drug with or immediately after meals may help prevent gastrointestinal discomfort.

Integumentary System: Dermatological manifestations sometimes accompanied by fever have included scarlatiniform or morbilliform rashes.

Hemopoietic System: Hemopoietic complications, some fatal, have occasionally been reported in association with administration of phenytoin. These have included thrombocytopenia, leukopenia, granulocytopenia agranulocytosis, and pancytopenia.

Other: Gingival hyperplasia occurs frequently; this incidence may be reduced by good oral hygiene including gum massage, frequent brushing and appropriate dental care. Polyarthropathy and hirsutism occu occasionally. Hyperglycemia has been reported. Toxic hepatitis, liver damage and periarteritis nodosa may occur and can be fatal.

\section{MANAGEMENT OF OVERDOSAGE}

The mean lethal dose in adults is estimated to be 2 to 5 grams. The cardinal initia symptoms are hystagmus, ataxia and dysarthria. The patient then becomes comatose, the pupils are unresponsive and hypotension occurs. Death is due to respiratory depression and apnea Treatment is nonspecific since there is no known antidote. First, the stomach should be emptied. If the gag reflex is absent, the airway should be supported. Oxycen, vasopressors and as sisted ventilation may be necessary for central nervous system, respiratory and cardiovascular depression. Finally, hemodialysis can be considered since phenytoin is not completely bound to plasma proteins. DOSAGE AND ADMINISTRATION

Dosage should be individualized to provide maximum benefit. In some cases, serum blood level determinations may be necessary for optimal dosage adjustments - the clinically effective serum level is usually $10-20 \mathrm{mcg} / \mathrm{mL}$

Adult Dose: Patients who have received no previous treatment may be started on one $100 \mathrm{mg}$ Dilantin Capsule three times daily and the dose then adjusted to suit individual requirements.

Pediatric Dose: Initially, $5 \mathrm{mg} / \mathrm{kg} /$ day in two or three equally divided doses, with subsequent dosage individualized to a maximum of $300 \mathrm{mg}$ daily. A recommended daily maintenance dosage is usually 4 to $8 \mathrm{mg} / \mathrm{kg}$. Children over 6 years old may require the minimum adult dose $(300 \mathrm{mg} /$ day). Pediatric dosage forms available include a $30 \mathrm{mo}$ capsule, a 50 mg palatably flavoured Infatab, or an oral suspension form containing $30 \mathrm{mg}$ of Dilantin in each $5 \mathrm{~mL}$.

Alternative Dose: Once-a-day dosage for adults with $300 \mathrm{mo}$ of Dilantin may be considered if seizure control is established with divided doses of three $100 \mathrm{mg}$ Capsules daily.

HOW SUPPLIED

Dilantin $100 \mathrm{mg}$ Capsules; in bottles of $100 \& 1000$.

Complete prescribing information available upon request.

\section{PARKE-DAVIS}

Parke-Davis Canada Inc. Scarborough, Ontario

*Reg. T.M. Parke Davis \& Compary

Parke-Davis Canada inc., auth. user 
Indlcations and Clinical Use

Tegretol is indicated for the symptomatic relief of pain of trigeminal neuralgia only during periods of exacerbation of true or primary trigeminal neuralgia (tic douleureux). It should not be used preventively during periods of remission. In some patients, Tegretol has relieved glossopharyngeal neuralgia. For patients who fail to respond to Tegretol, or who are sensitive to the drug, recourse to other accepted measures must be considered.

Tegretol is not a simple analgesic and should not be used to relieve trivial facial pains

1) in the management of psychomotor (temporal lobe) epilepsy and

2) as an adjunct, in some patients with secondary or partial epilepsy with complex symptomatology or sec ondarily generalized seizures, when administered in

combination with other antiepileptic medication. 3) as an alternative medication in patients with generalized tonic-clonic seizures who are expenticonvulsant drugs.

Tegretol is essentially ineffective in controlling petit teral seizures, and does not prevent the generalization of epileptic discharge.

\section{of epileptic discharge}

Tegretol should not be administered to patients with a history of hepatic disease or serious blood disorder Tegretol should not be administered immediately before, in conjunction with, or immediately after a monoamine oxidase inhibitor. When it seems desirable to administer Tegretol to a patient who has been receiving an MAO inhibitor, there should be as long a drug-free interval as the clinical condition allows, but in no cas Tegretol should be low initially, and increased very gradually.

Tegretol should not be administered to patients presenting atrioventricular heart block.

Sate use in pregnancy has not been established. Therefore, Tegretol should not be administered during the first three mont hs of pregnancy. Tegretol stiould not be given to women of childbearing potential unless, in the opinion of the physician, the expected benefits to the patient outweigh the possible risk to the foetus (See Reproductive Studies). Because of demonstrated toxicity in nursing animals, Tegretol should not be administered to nursing mothers.

Because of the similarity of chemical structure.

Tegretol should not be administered to patients with known hypersensitivity to any of the tricyclic compounds, such as amitriptyline, trimipramine, imipramine, or their analogues or metabolites.

Warnings

Although reported infrequently, serious adverse effects have been observed during the use of Tegretol. Agran locytosis and aplastic anemia have occurred in a few
instances with a fatal outcome. Leucopenia, thrombocytopenla and hepatocellular and cholestatic jaundice have also been reported. It is, therefore, important that Tegretol should be used carefully and close clinical and frequent laboralory supervision should be maintained throughout treaiment in order to detect as early as possible

Long-term toxicity studies in rats indicated a potential carcinogenic risk. Therefore, the possible risk of drug use must be weighed against the polentlal benefits before prescribing carbamazepine to individual patients.

Monitoring of Haematological and Other Adverse Peac tions: Complete blood studies, including platelet counts, and evaluation of hepatic and renal function and urinalysis should be carried out before treatment is instituted. Careful clinical and laboratory supervision should be maintained throughout treatment, including frequent performance of complete blood counts, in order to detect any early signs or symptoms of blood dyscrasia. Should any signs or symptoms or abnorma laboratory findings suggestive of blood dyscrasia or liver disorder occur, Tegretol should be immediately Continued until the case is carefully reassessed. Urinary Retention and increased intraocular Pressure Because of its anticholinergic action. Tegretol should be given cautiously, if at all, to patients with increased intraocular pressure or urinary retention. Such patients should be followed closely while taking the orug. Occurrence of Behavioural Disorders. Because it is closely related to the other tricyclic drugs, there is some possibility that Tegretol might activate a latent psychosis, or, in elderly patients, produce agitation or
confusion, especially when combined with other drugs Caution should also be exercised in alcoholics.

Use in Patients with Cardiovascular Disorders: Tegretol should be used cautiously in patients with a history of coronary artery disease, organic heart disease, or concoronary artery disease, organic heart disease, or conpected, an E.K.G. should be performed before administering Tegretol, in order to exclude patients with

atrioventricular block.

Use in Patients taking Oral Contraceptives: In women Use in Patients taking Oral Contraceptives: In women traceptives may be adversely affected; such patients traceptives may be adversely affected; such patients should accordingly be advised to use som

Driving and operating Hazardous Machinery: Because

dizziness and drowsiness are possible side effects of

Tegretol, patients shoud be warned about the possible hazards of operating machinery or driving automobiles.
Adverse Reactions

The reactions which have been most frequently reported with Tegretol are drowsiness, unsteadiness on the feet, vertigo, dizziness, gastrointestinal disturbances, and nausea. These reactions usually occur only during the initial phase of therapy. They have rarely necessitated discontinuing Tegretol therapy, and can be minimized by initiating treatment at a low dosage. The more serious adverse reactions observed are the haematologic, hepatic, cardiovascular and derma logic reactions, which require discontinuation of therapy

The following adverse reactions have been reported Haematological reactions: Transitory leucopenia, esinophilia, leucocytosis, thrombocytopenic purpur agranulocylosis, macrocytic anemia and aplastic Hepatic disturbances: During the long-term administration of Tegretol, abnormalities in liver function tests and cholestatic or hepatocellular jaundice have been observed.

Dermatological reactions: The following reactions occurred during treatment with Tegretol: skin sensitivity reactions and rashes, erythematous rashes, pruritic eruptions, urticaria, photosensitivity, pigmentary changes, neurodermatitis and in rare cases StevensJohnson syndrome, exfoliative dermatitis, alopecia, diaphoresis, erythema multifor me, erythema nodosum,
aggravation of disseminated lupus erythematosus.
Neurological reactions: The reactions reported as occurring during treatment with Tegretol include ver-
tigo, somnolence, disturbances of coordination, contigo, somnolence, disturbances of coordination, condiplopia and oculomotor disturbances, speech disturbances abnormal involuntary movements and increase in motor seizures. In addition, peripheral neuritis and paresthesia, depression with agitation, talkativeness, nystagmus, and tinnitus have been reported but only very rarely. There have been some reports of paralysis and other symptoms of cerebral arterial insufficiency but no conclusive relationship

Cardiovascular systems: Recurrence of thrombophlebitis in patients with Stokes-Adams in patients with AV block, hypotension, syncope and collapse, edema, aggravation of coronary artery disease. Some of these complications (including myocardial infarction and arrhythmia) have been associ ated with other tricyclic compounds.

Genitourinary reactions: Urinary frequency, acute urinary retention, oliguria with elevated blood pressure. and impotence. Elevation of BUN, albuminuria and glycosuria also have been observed

Digestive tract: Disturbances associated with Tegretol therapy have included nausea, vomiting, gastric or abdominal discomfort, diarrhoea, anorexia and dryness of the mouth and throat, glossitis and stomatitis. Eyes: There is no conclusive evidence that Tegretol produces pathological changes in the cornea, lens or retina. However, it should be recognized that many phenothaz hes and relaled drugs have been shown to cause including slitlamp fundoscopy and tonometry, are recommended.

Other reactions reported during treatment with

Other reactions reported during treatment with aching joints and muscles, leg cramps and conjunctivitis.

\section{Dosage and Administration}

Use in Epilepsy (see Indications): A low initial daily Dosage should be adjusted to the needs of the ind ual patient.

Adults and Children over 12 years of age: Initially, 100 to $200 \mathrm{mg}$ once or twice a day depending on the severity of the case and previous therapeutic history. The initial cosage is progressively increased, until the best response is obtained, up to $600 \mathrm{mg}$ daily. The usual
optimal dosage is $600 \mathrm{mg}$ daily, but occasionally dosages up to 800 to $1000 \mathrm{mg}$ have been used for short periods. As soon as disappearance of seizures has been obtained and maintained, dosage should be reduced very gradually until a minimum effective dose in reached.

Use in-trigeminal neuralgia: The initial daily dosage should be small; $200 \mathrm{mg}$, taken in two doses of $100 \mathrm{mg}$ each is recommended. The total daily dosage can be increased by $200 \mathrm{mg}$ per day until relief of pain is obtained. This is usually achieved at a dosage between 200 and $800 \mathrm{mg}$ daily, but occasionally up to $1200 \mathrm{mg}$ per day may be necessary. As soon as relief of pain has been obtained and maintained, progressive reduction in dosage should be attempted until a minimum effective dosage is reached. Because trigeminal neuralgia is characterized by periods of remission, attempts should be made to reduce or discontinue the use of Tegretol at intervals of not more than 3 months, depending upon ual clinical course.

Prophylactic use of the drug in trigeminal neuralgia is

Tegretol should be taken in two or three divided doses daily, with meals whenever possible.

Dosage Forms

Tegretol is available as a $200 \mathrm{mg}$ white, round, flat. bevelled-edged, double-scored tablet, imprinted with AvalaiGY monogram.

Bottles of 50 and 500 tablets. Protect from heat and

Full information available on request.

See outside back cover

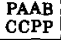

Geigy

Rivotril

\section{Rx Summary}

Indications

Alone or adjunctively in the management of myoclonic, akinetic and petit mal variant seizures. In petit mal (absence spells) when response to succinimides unsatisfactory.

Contraindications

Hypersensitivity to benzodiazepines. Clinical or biochemical evidence of significant liver disease. Narrow angle glaucoma.

Warnings

Use in pregnancy: in women who are or who may become pregnant when potential benefits warrant possible risks to mother and fetus. Mothers

receiving 'Rivotril' should not breastfeed infants.

Consider the risk/benefit of long-term use.

particularly in children.

Precautions

Use of multiple anticonvulsants may increase CNS depression and dosage of each may need adjustment downward. Avoid abrupt withdrawal and consider substitution with another anticonvulsant during withdrawal.

May cause paradoxical increase in seizure activity or new seizure types. Concomitant use with valproic acid may produce absence status Caution patients against engaging in hazardous activities requiring complete mental alertness or physical coordination. Warn against concomitant use of alcohol or other CNS depressant drugs. Monitor patients who may be prone to increasing the dosage on their own accord.

Administer with caution to patients with impaired renal function. Periodic liver function tests and blood counts may be advisable during long-term

therapy

Institute therapy with caution in patients with chronic respiratory disease because of possible hypersecretion in upper respiratory tract.

\section{Adverse Reactions} $30 \%$ of patients but these effects have diminished with time Behavioural problems have been noted in approximately $25 \%$ and increased salivation in $7 \%$ of patients.

Consult monograph for complete list of reported adverse reactions.

Dosage

Depends upon age and must be determined according to clinical response and tolerance. Daily requirements should be given in 2 or 3 divided doses and if not equal, the larger dose should be given before retiring

Children up to 10 years $(30 \mathrm{~kg})$ : Initial dose should be 0.01 to $0.03 \mathrm{mg} / \mathrm{kg} / \mathrm{day}$ and should not exceed $0.05 \mathrm{mg} / \mathrm{kg} /$ day. Increase dose by 0.25 to $0.5 \mathrm{mg}$ every third day to maintenance dose of 0.1 to 0.2 $\mathrm{mg} / \mathrm{kg} /$ day providing optimum response.

Adults: Initial dose should not exceed $1.5 \mathrm{mg} /$ day. Increase dose by 0.5 to $1.0 \mathrm{mg}$ every third day to maintenance dose of 8 to $10 \mathrm{mg} /$ day with optimum be administered with caution.

Bear in mind possible increased depressant effects whenever 'Rivotril' is added to an existing anticonvulsant regimen.

Supply

Orange, cylindrical, biplane tablets with RIVOTRIL 0.5 engraved on one face, and single scored on the other with ROCHE above and $\mathrm{C}$ below the score, each containing $0.5 \mathrm{mg}$ clonazepam 

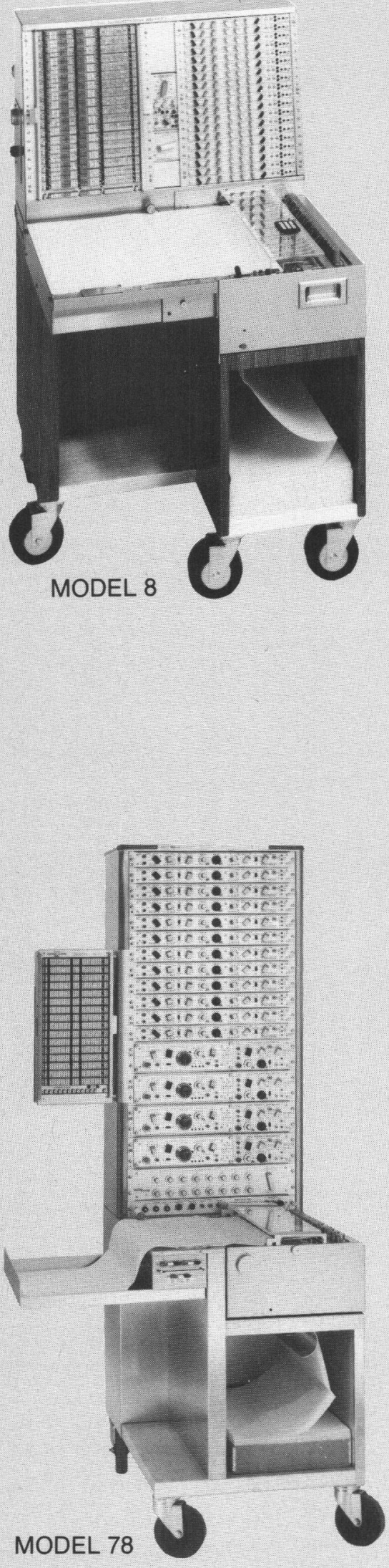

\section{POLYSOMNOGRAPHIC RECORDING FOR CLINIC OR RESEARCH}

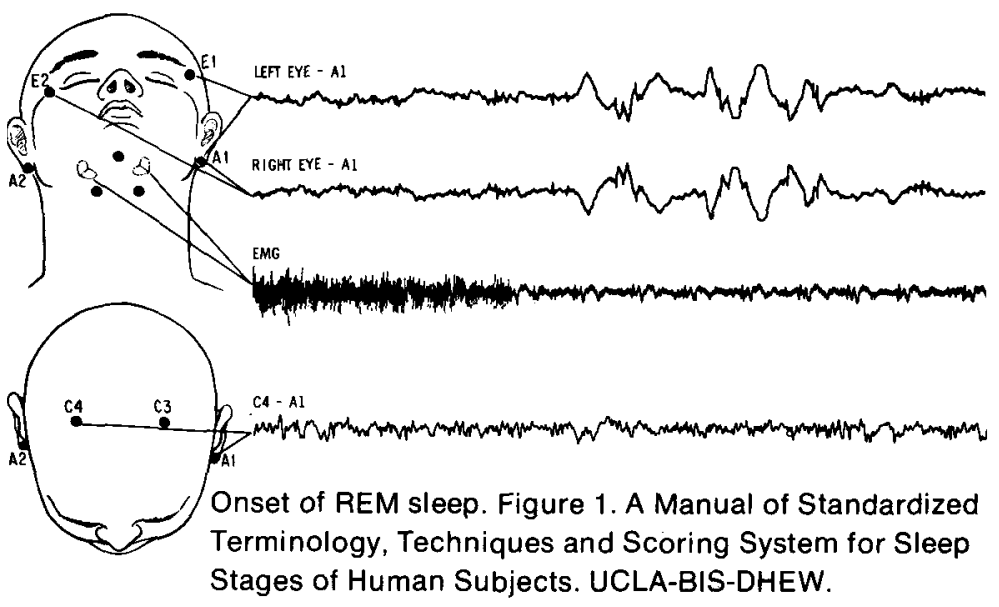

For multiple parameter recording of sleep-wake disorders in the clinical or the research setting, Grass Polygraphs and EEGs have the reliability and flexibility required.

For research applications, the Model 78 Polygraph with a wide selection of interchangeable signal conditioning preamplifiers allows recording several channels of EEG, EOG, EMG, ENG, temperature, respiration, EKG, blood gases, etc., with convenience and ease. A wide range of transducers, recording accessories, plus multiple chart speeds, including the widely used $10 \mathrm{~mm} / \mathrm{sec}$, provide a complete sleep-wake recording system.

For dual purpose applications where the primary interest is in clinical EEG and the secondary interest involves multiple parameter sleep studies, the Model 8 $E E G$ is the instrument of choice.

For dependable long-term studies - rely on Grass, recording bioelectric activity since 1935 .

Write for further information on a system to meet your polysomnographic recording needs.

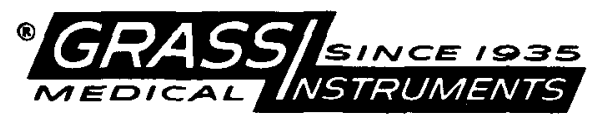

QUINCY, MASS. $02169 \cdot 617 / 773-0002$ 


\section{These minors are victims}
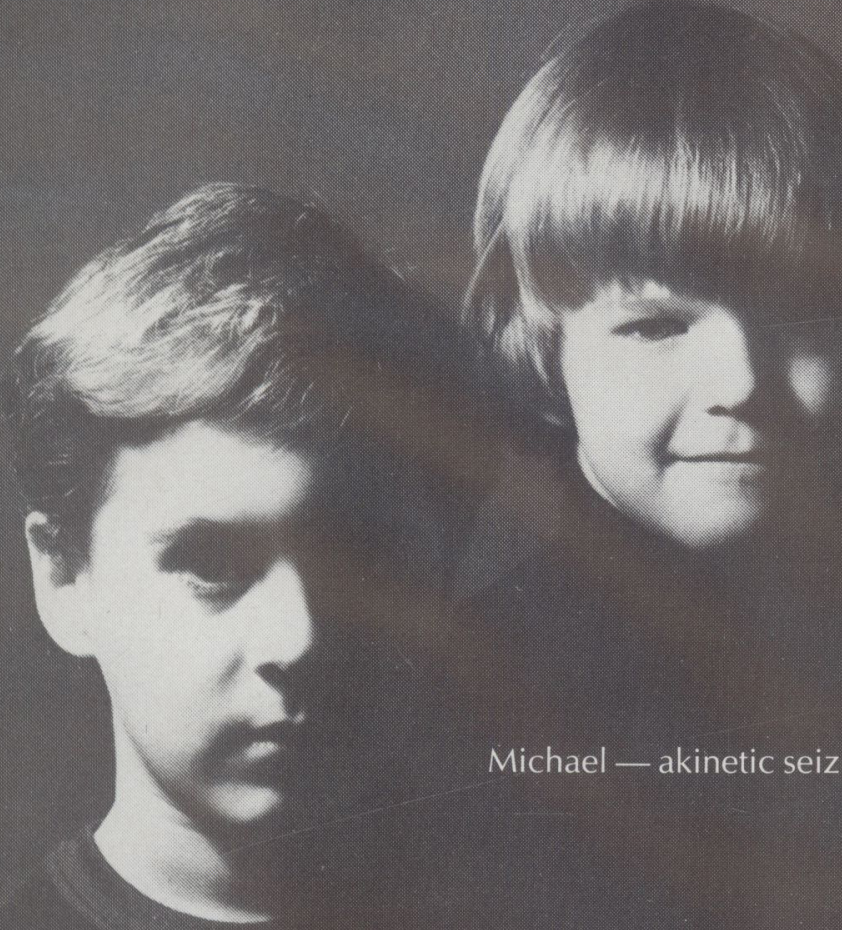

Michael — akinetic seizures

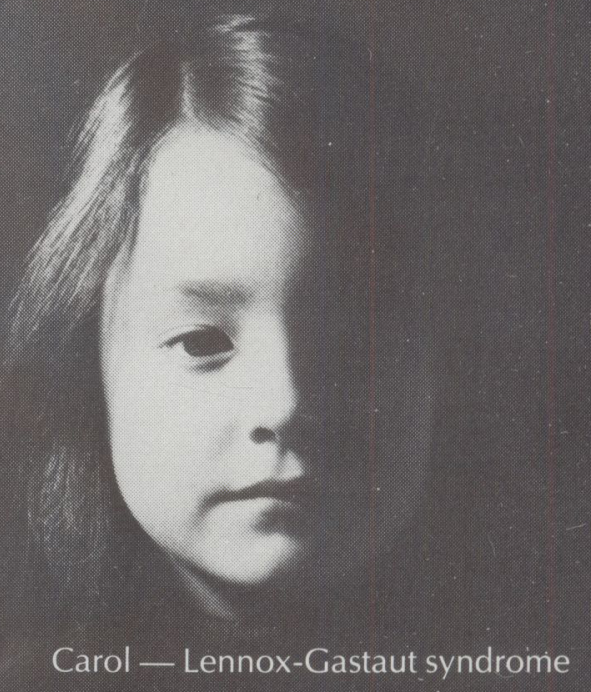

Jean - myoclonic seizures

These children, victims of minor motor seizures, may benefit from the many advantages offered by 'Rivotril'.

- Effective in reducing the frequency and/or severity of a variety of epileptic seizures

- akinetic seizures

- myoclonic seizures

- Lennox-Gastaut syndrome (petit mal variant)

- absence seizures (where succinimide therapy has failed)

- flexible dosage regimen encourages patient compliance

- no reports of incompatibility with a ketogenic diet

- economical, for long-term therapy

- may be used concomitantly with most other anticonvulsants
'Rivotril' has not been associated with the severe side effects seen with some other anticonvulsant medications.

- No reports of serious side effects, such as hepatotoxicity.

- Very low incidence of nausea and G.I. upsets. 1

- No serious problems of drug interaction. (eg. ASA)

- Proven safety record in long-term administration.

- Drowsiness, which may occur, is generally dose-related and may be well controlled with proper dosage adjustment. 2,3 

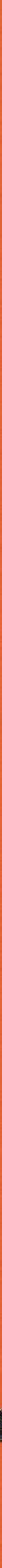

preferred by Parkinson patients 


\section{In Parkinson Therapy:}
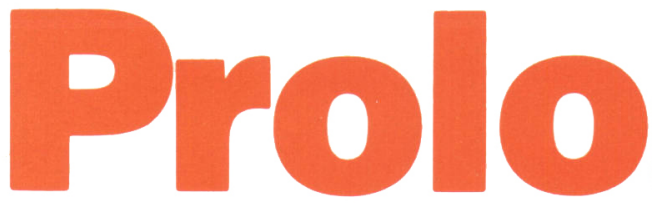

(B)

\section{4 parts L-dopa: 1 part benserazide}

\section{For the response you expect... without the frequency of peripheral side effects}

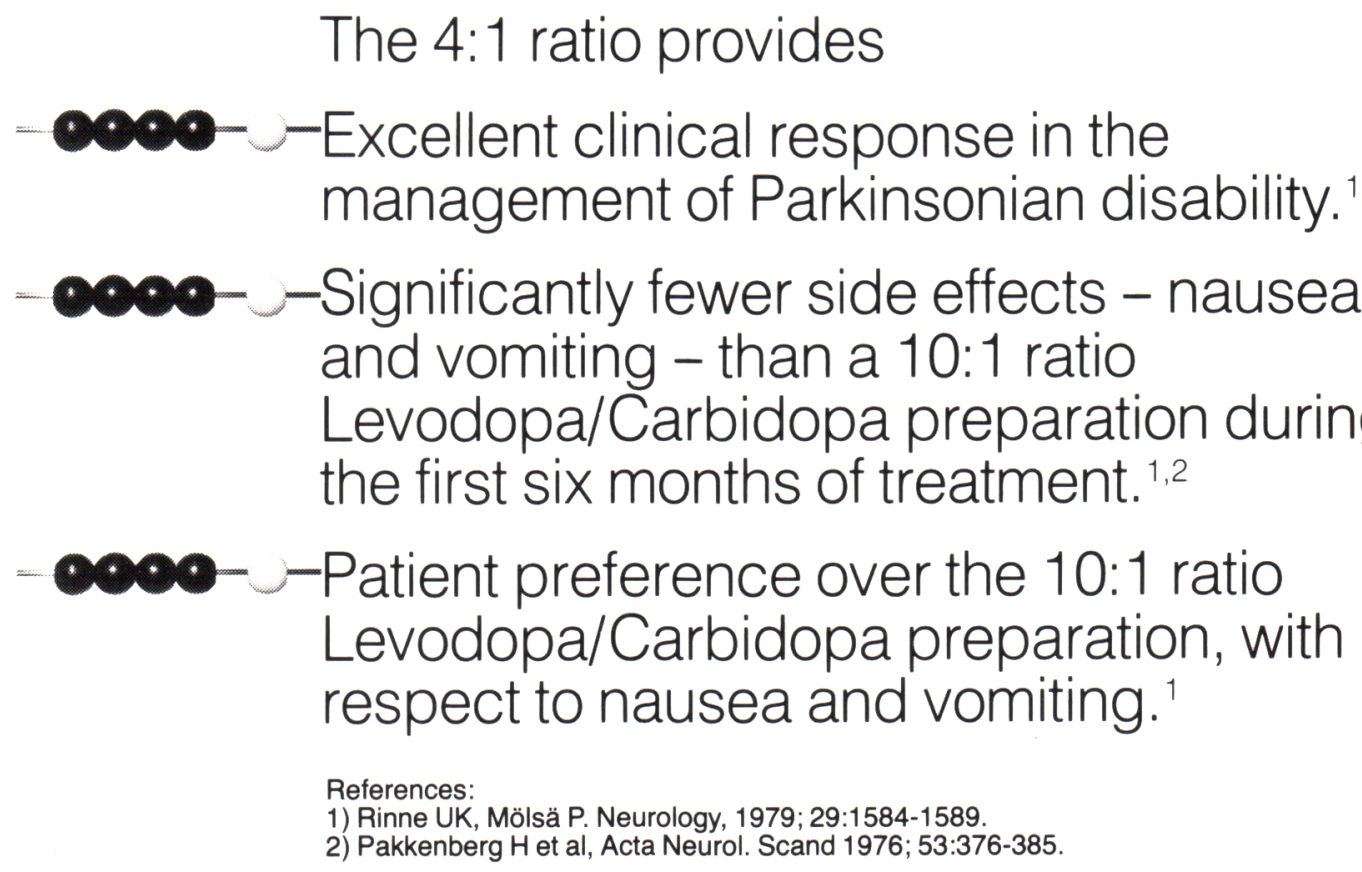

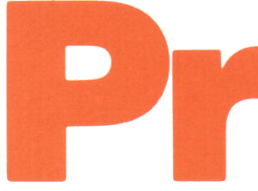
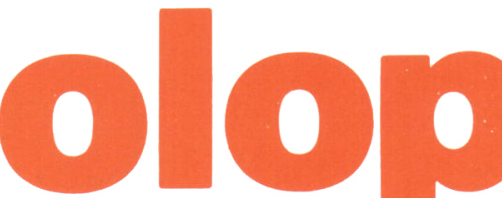

right from the start
(B)
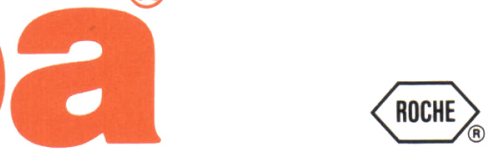

Original Research in Medicine and Chemistry

Reg. Trade Mark

Can. 0094

See page xvii for brief prescribing information.
The parkinson foundation of canada
Information and companionship for Parkinson patients is available from the Parkinson Foundation of Canada.

Please write or call: Suite 232, ManuLife Centre, 55 Bloor St.West, Toronto, Ontario M4W 1A6. Telephone: (416) 964-1155. 


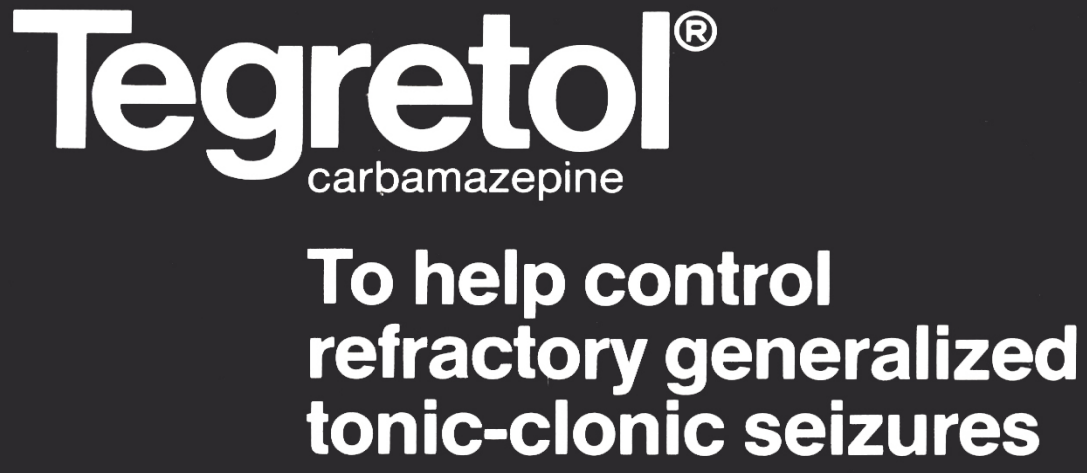

without excessive sedation

\begin{abstract}
00000
00008090909

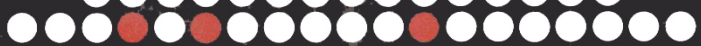

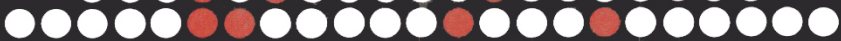

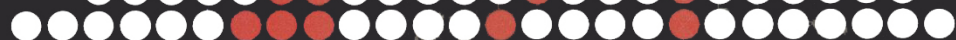

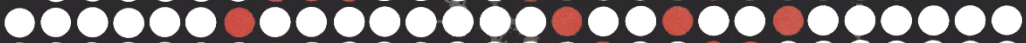

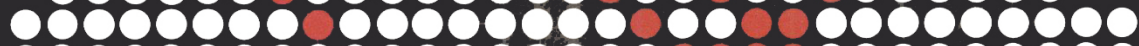

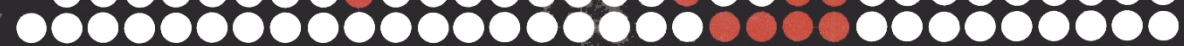

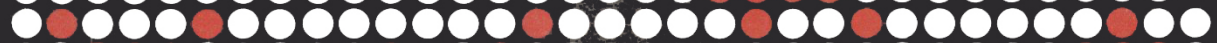

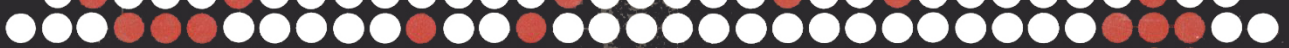

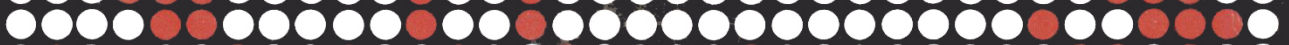

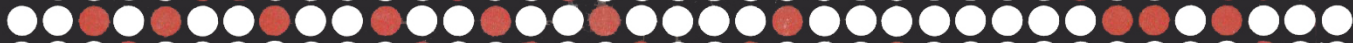

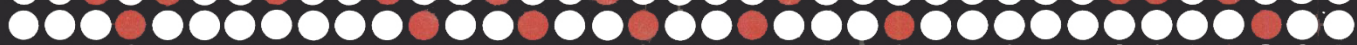

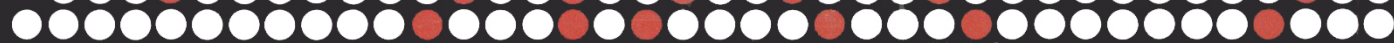

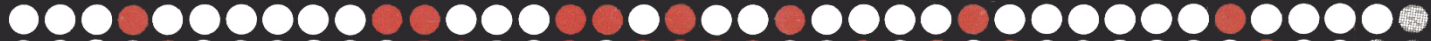

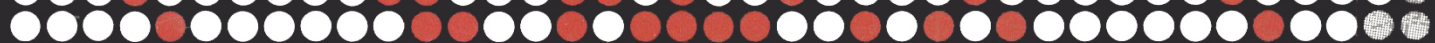

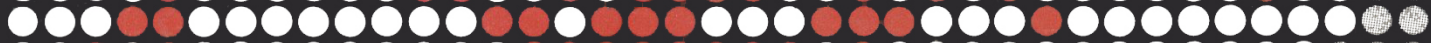

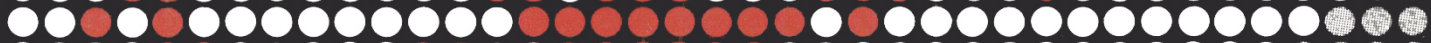

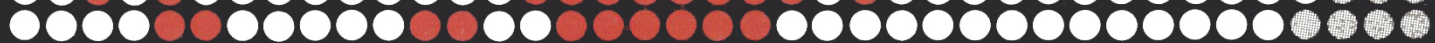

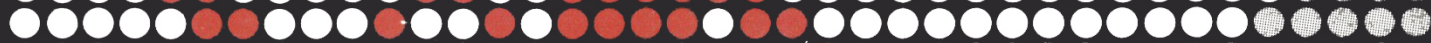

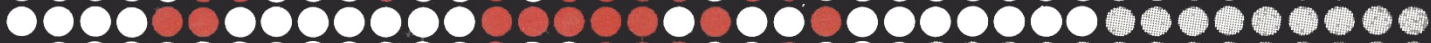

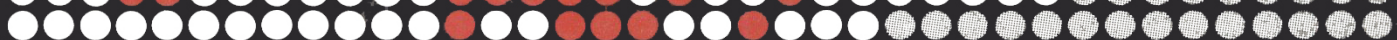

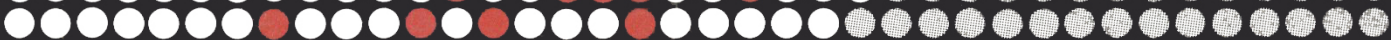

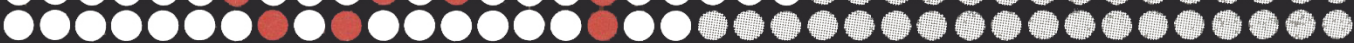

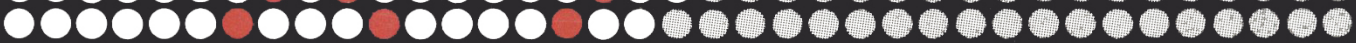

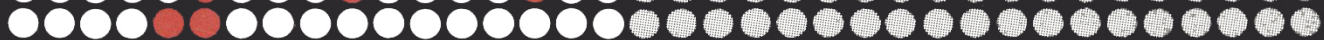

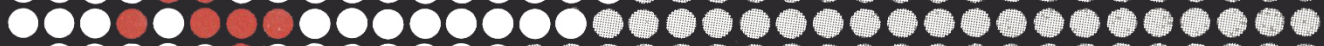

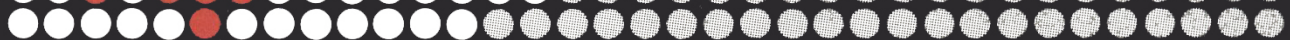

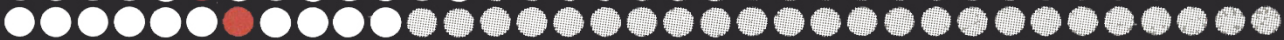
000000000000000000000000 0000000000000000000000000000

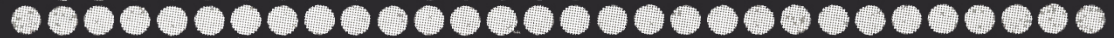
000000000000000000000000 000000000000000000000000 00000000000000000000000000 000000000000000000000000 0000000000000000000000000 0900000000090000000000000000 0000000000000000000000000

0000000000000000000000000

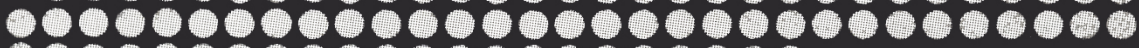
\$000000000000000000 00900000000000000

000000900000000000 090000000000000006 000000000000000000 00000000000000000
\end{abstract}




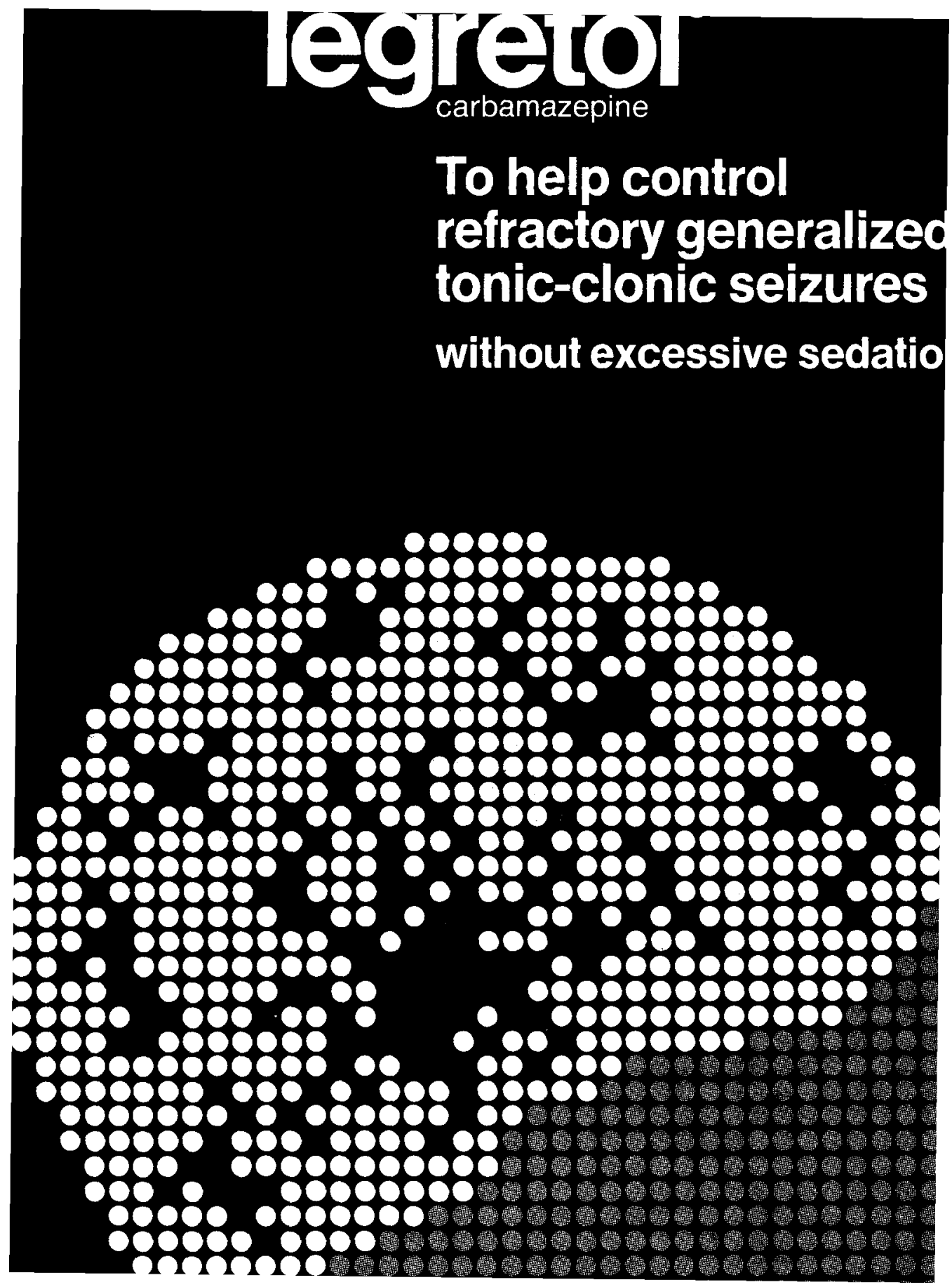

